\title{
Gambaran Proses Trust-Building pada Interaksi Pengguna Situs Perkencanan Daring
}

\author{
THERESIA CHRISTINA OCTAVIOLAN \& RAHKMAN ARDI* \\ Fakultas Psikologi Universitas Airlangga
}

\begin{abstract}
ABSTRAK
Berkembangnya teknologi kini memudahkan kehidupan manusia untuk berinteraksi. Salah satunya adalah kemudahan dalam mencari pasangan dengan mengakses situs perkencanan daring. Proses interaksi yang terjadi tidak berbeda dengan interaksi secara luring karena membutuhkan satu aspek penting yaitu kepercayaan (trust). Maka dari itu penelitian ini bertujuan untuk mengetahui bagaimana proses trust-building pada interaksi pengguna situs perkencanan daring. Penelitian kualitatif ini menggunakan tipe penelitian studi kasus intrinsik yang dilakukan pada 3 partisipan pengguna situs perkencanan daring baik yang sudah tidak menggunakan maupun masih menggunakan hingga saat ini. Situs perkencanan daring yang digunakan oleh partisipan antara lain seperti Tinder, Secret, dan Whisper. Hasil analisis data pada penelitian ini menunjukkan beberapa tema yang muncul yaitu, berawal dari motif/intensi, adanya strategi self-presentation dalam berinteraksi, sehingga feeling connected, intimacy, dan berakhir dengan terbangunnya trust dengan orang lain.
\end{abstract}

Kata kunci: interaksi, perkencanan daring, trust-building

\section{ABSTRACT}

The developing technology now makes human life easier to do. One of them is finding a partner by accessing dating sites. The interaction process that occurs is no different from engaging interactions because it requires one important aspect, namely trust. Therefore, this study aims to see how the trustbuilding process is in the interaction of dating site users. This qualitative research uses an intrinsic case study type of research conducted on 3 participants who use dating sites who dare to use or use it until now. The dating sites used by participants included Tinder, Secret, and Whisper. The results of data analysis in this study indicate several themes that arise, starting from the motive/intention, the existence of self-presentation strategies in interacting, so that feelings of connection, intimacy, and ending with the building of trust with other people.

Keywords: interaction, online dating, trust-building

Buletin Penelitian Psikologi dan Kesehatan Mental (BRPKM), 2021, Vol. 1(1), 577-584

*Alamat korespondensi: Fakultas Psikologi Universitas Airlangga, Kampus B Universitas Airlangga Jalan Airlangga 4-6 Surabaya 60286. Surel: rahkman.ardi@psikologi.unair.ac.id Common Attribution License (CC-BY-4.0) (http://creativecommons.org/licenses/by/4.0), sehingga penggunaan, distribusi, reproduksi dalam media apapun atas artikel ini tidak dibatasi, selama sumber aslinya disitir dengan baik. 


\section{P E N D A H U L U A N}

Saat ini internet semakin banyak dimanfaatkan oleh masyarakat dengan layanan yang diberikan seperti untuk mendapatkan relasi teman baru, jodoh atau mencari pasangan. Salah satu akses yang tidak kalah populer di kalangan pengguna internet adalah situs maupun aplikasi perkencanan daring. Seperti yang dilansir dalam yougov.com pada tahun 2017 (Staff, 2017), telah dilakukan pengumpulan data secara daring menggunakan panel yougov pada lebih dari 5 juta orang di seluruh dunia dan ukuran sampel sebesar 2.274 untuk mendata internet dating ranking. Penelitian mereka mendapatkan sepertiga dari pengguna internet di Indonesia telah menggunakan aplikasi kencan daring, yaitu sebesar 34\%, dengan presentase pengguna paling tinggi adalah pada generasi milenial, yaitu sebesar $36 \%$. Mereka juga menemukan dua platform kencan daring yang paling banyak diketahui dan digunakan oleh pengguna di Indonesia, yaitu BeeTalk dan Tinder (Staff, 2017).

Disamping itu terdapat penelitian lebih lanjut menemukan bahwa pengguna situs perkencanan daring cenderung meningkatkan penipuan akan self-presentation untuk terlihat lebih menarik ketika berinteraksi dengan kemungkinan pasangan yang diinginkan. Selain itu, internet juga dapat digunakan untuk tujuan seksual. Penelitian yang menyatakan $45 \%$ wanita dan $55 \%$ pria memiliki tujuan seksual sehingga juga akan menimbulkan risiko akan penyakit seksual. Tidak hanya itu, scam juga dapat terjadi dalam situs perkencanan daring yang dapat menimbulkan kerugian finansial dan emosional (Kee \& Yazdanifard, 2015). Salah satu kasus yang pernah terjadi adalah seorang wanita berusaha 67 tahun ditemukan meninggal dibunuh setelah menjadi korban penipuan (Powell, 2013). Hal inilah yang kemudian mengarahkan pada penggunaan situs perkencanan daring. Tidak hanya kenyamanan yang dirasakan ketika menggunakan internet, menurut sebuah penelitian, trust atau kepercayaan menjadi salah satu faktor yang mengarahkan individu untuk menggunakan situs perkencanan daring.

Pokok persoalan atau bahasan yang akan dikaji dalam penelitian mengenai trust-building pengguna situs perkencanan daring ditinjau dari interaksi yang terjalin baik itu secara online maupun offline dan bahkan mungkin hingga mengarah pada romantic relationship. Meskipun terdapat beberapa penelitian yang mengkaji topik yang sama, namun penelitian ini dilakukan pada golongan anak muda di Indonesia dengan budaya masyarakat yang cenderung kolektivis (memiliki nilai tinggi pada grup/kelompok) (Mangundjaya, 2013), berbeda dengan penelitian sebelumnya yang memiliki kultur yang berbeda dengan Indonesia, yaitu cenderung individualis seperti beberapa penelitian yang dilakukan oleh Lawson \& Leck (2006) di Pennsylvania, Amerika Serikat, Obada-Obieh dkk. (2017) di California, Amerika Serikat, dan Whitty \& Gavin (2001) di Sydney, Australia. Oleh karena itu, dalam kultur yang berbeda antara kolektivis dan individualis terdapat pula perbedaan dalam membentuk kepercayaan itu sendiri, seperti dalam penelitian (Doney dkk., 1998) mengenai pengaruh kultur terhadap perkembangan kepercayaan dalam sebuah hubungan.

Kolektivisme sendiri berkaitan dengan masyarakat yang dimana orang akan terintegrasi dalam pertalian yang kuat pada kelompok (Mangundjaya, 2013). Berbeda dengan sifat individualis yang menekankan pada right to privacy, kolektivis justru menekankan sharing (Brewer \& Chen, 2007). Namun sebagaimana yang terjadi di Indonesia dengan kultur kolektivis sendiri belum tentu individu tidak menjaga privasinya yang nantinya berkaitan dengan bagaimana membangun kepercayaan dengan orang lain. Privasi sendiri berbicara mengenai bagaimana individu dan kelompok mengontrol maupun meregulasi akses terhadap diri mereka sendiri (Margulis, 2011). 
Melihat fenomena yang marak terjadi hal itulah perlunya mengkaji topik kepercayaan dalam platform perkencanan daring dengan adanya berbagai kebohongan dan hal-hal lainnya yang terjadi di dalam perkencanan daring dibutuhkan proses untuk membangun kepercayaan diantara individu sebagai pengguna situs maupun aplikasi kencan daring yang melakukan komunikasi dan interaksi melalui media tersebut hingga kemungkinan untuk bertemu secara langsung atau berkomunikasi secara tatap muka. Tujuan dari penelitian ini sendiri adalah untuk mengetahui bagaimana proses trust-building pada orang yang berinteraksi dan berkomunikasi menggunakan situs maupun aplikasi online dating.

Penelitian ini menggunakan teori dasar social presence telah digunakan oleh beberapa peneliti dalam dua cara yang berbeda, yaitu untuk mengarah pada properti media dalam komunikasi yang termediasi dan untuk mengarah pada persepsi, perilaku, maupun sikap partisipan dalam interaksi yang termediasi. Social presence juga dapat meningkatkan trust dapat mereduksi ambiguitas serta risiko yang diterima sehingga menghasilkan sikap yang positif termasuk persepsi bahwa teknologi dapat dipercaya, selain itu juga menyediakan isyarat untuk membangun kepercayaan seperti bahasa tubuh maupun isyarat fisik lainnya (Lankton dkk., 2015).

\section{Desain Penelitian}

\section{E T ODE}

Dalam penelitian ini, peneliti menggunakan pendekatan penelitian kualitatif. Tipe penelitian kualitatif yang digunakan dalam penelitian ini adalah menggunakan pendekatan studi kasus untuk mengeksplorasi suatu kasus atau beberapa kasus melalui pengumpulan data yang mendalam dan melibatkan berbagai sumber informasi (Creswell \& Poth, 2016). Tipe penelitian studi kasus dilakukan dalam penelitian ini sesuai dengan fokus penelitian untuk menjawab bagaimana trust-building dalam interaksi melalui situs perkencanan daring.

\section{Strategi Pengumpulan Data}

Teknik pengambilan data dalam penelitian ini adalah wawancara. Wawancara dilakukan secara tatap muka dengan partisipan yang melibatkan pertanyaan terbuka dan dimaksudkan untuk memperoleh pendapat dan pandangan dari partisipan (Creswell \& Creswell, 2017). Jenis wawancara yang digunakan dalam penelitian ini adalah wawancara semi berstrukur, dengan memulai pada cakupan isu yang ada pada pedoman wawancara. Wawancara dilakukan sebanyak 1 kali pada masing-masing partisipan.

\section{Partisipan}

Partisipan dalam penelitian ini diperoleh dengan menentukan kriteria terlebih dahulu untuk memperoleh hasil penelitian yang sesuai dengan topik. Kemudian memberikan pengajuan izin (informed consent) agar subjek setuju menjadi partisipan dalam penelitian ini Adapun kriteria partisipan dalam penelitian ini sebagai berikut: (1) Pernah atau sedang menggunakan situs perkencanan daring apa saja selama kurang lebih satu bulan secara intens, (2) Pernah atau sedang menjalin hubungan dekat maupun berpacaran dengan orang yang dikenal melalui situs perkencanan daring. Karakteristik partisipan dalam penelitian ini yakni berjumlah tiga orang dengan dua orang wanita dan satu orang pria, yang berumur kurang lebih 21-22 tahun, kemudian memiliki profesi sebagai mahasiswa Psikologi di salah satu Universitas X dan juga wiraswasta. Teknik yang digunakan dalam penelitian ini adalah purposive sampling sebelum mengumpulkan data, sehingga partisipan yang dibutuhkan disesuaikan dengan kriteria partisipan pada topik penelitian ini (Poerwandari \& Hassan, 1999). Pada saat melakukan wawancara, peneliti tetap fokus pada pertanyaan dan diusahakan untuk tepat waktu, juga memberikan rasa hormat dan rasa menghargai. 
Teknik pemantapan kredibilitas yang dilakukan dalam penelitian ini adalah dengan melakukan member checks, dimana hal tersebut dilakukan dengan memberikan hasil penemuan, analisis data, serta intrepretasi yang telah dilakukan peneliti untuk mendapatkan pandangan dari partisipan untuk menilai keakuratan serta kredibilitas dari hasil penemuan dalam penelitian ini (Creswell \& Poth, 2016). Teknik member checks dilakukan dengan memberikan hasil analisis data yang telah disusun oleh peneliti pada partisipan untuk memastikan kembali apakah interpretasi serta analisis data yang dilakukan telah sesuai dengan kondisi partisipan yang sebenarnya.

\section{Analisis Data}

Teknik analisis data yang digunakan dalam penelitian ini adalah menggunakan teknik analisis tema. Teknik ini merupakan teknik yang paling umum dan sering digunakan dalam penelitian kualitatif atau disebut juga dengan interpretative thematic analysis. Analisis tematik mengarah pada metode untuk mengidentifikasi, menganalisis serta melaporkan pola (tema) dalam data. Teknik analisis tematik yang digunakan untuk menganalisis data dalam penelitian ini adalah menggunakan analisis data driven, yaitu pengumpulan data kasar dari sampel penelitian yang kemudian membentuk kode-kode berdasarkan informasi/data yang diperoleh yang berasal dari wawancara.

\section{HAS IL P EN EL IT IAN}

Berdasarkan hasil penelitian, terdapat proses bagaimana kepercayaan terbangun selama interaksi maupun komunikasi antara ketiga Partisipan dengan orang-orang yang mereka kenali melalui situs perkencanan daring. Proses trust-building yang terjadi berawal dari motif serta intensi menggunakan situs perkencanan daring yang melibatkan bagaimana individu melakukan self-presentation dalam berinteraksi maupun membangun kepercayaan dengan orang lain sehingga mengarahkan pada terbangunnya kepercayaan antara dua orang dalam hubungan interpersonal yang telah terjalin. Proses trust-building yang terjadi berawal dari motif serta intensi menggunakan situs perkencanan daring yang melibatkan bagaimana individu melakukan self-presentation dalam berinteraksi maupun membangun kepercayaan dengan orang lain sehingga mengarahkan pada terbangunnya kepercayaan antara dua orang dalam hubungan interpersonal yang telah terjalin.

Jika dikaji dengan teori dasar, yakni social presence nampak pada interaksi serta komunikasi yang terjalin pada ketiga subjek selama menggunakan situs perkencanan daring, melalui isyarat sosial yang muncul ketika dua orang berkomunikasi dalam medium yang berbeda. Tidak hanya berkomunikasi dalam situs itu sendiri, tetapi juga berlanjut pada platform media sosial lainnya dengan saling berukar kontak dan pribadi. Proses komunikasi yang telah terjalin melalui mediasi internet, membuat ketiga subjek membangun hubungan interpersonal yang lebih dekat dengan beberapa orang yang mereka temui melalui situs perkencanan daring, sehingga muncul adanya proximity maupun similarity. Hal tersebut memunculkan adanya perasaan seperti sedang bersama orang lain/presence dalam dunia maya meskipun tidak bertemu tatap muka, seperti partisipan dalam penelitian ini yang berbicara melalui video call, saling memberi kabar melalui pesan (chat), dan juga komunikasi yang intens sehingga saling terbuka satu sama lain mengenai pribadi masing-masing. Hal tersebut membuat pengguna situs merasakan social presence yang lebih besar, sejalan dengan hasil penelitian yang dilakukan oleh (Jung dkk., 2017).

Ketiga subjek dalam penelitian ini memiliki motif serta intensi yang mengarahkan pada hal yang sama, yaitu keinginan untuk mencari teman untuk berbicara serta mendapatkan pengalaman baru dari orangorang baru yang ditemuinya. Selain itu terdapat intensi untuk mencari pasangan/pacar. Hal ini sesuai 
dengan penelitian yang dilakukan oleh (Valkenburg \& Peter, 2007), bahwa pengguna internet yang berstatus masih lajang pernah mengunjungi situs perkencanan daring untuk mendapatkan pasangan. Sesuai dengan pernyataan dalam penelitian (M. Whitty \& Gavin, 2001) bahwa pengguna komputer memiliki kesadaran diri yang kurang untuk dievaluasi secara sosial sehingga memungkinkan terjadinya pengungkapan diri meskipun tetap menjaga jarak dan ruang pribadi. Self-disclosure atau keterbukaan diri yang dilakukan oleh ketiga subjek berbeda berdasarkan bagaimana mereka ingin menceritakan maupun menampilkan diri mereka pada orang lain baik secara online maupun offline. Karena proses bersama akan keterbukaan diri merupakan dasar ikatan kepercayaan yang dapat membentuk sebuah hubungan (Lawson \& Leck, 2006). Selain itu, karakteristik individu sebagai bagian dari strategi selfpresentation juga berkaitan pada proses membangun kepercayaan yaitu prediction process, dimana individu memprediksi perilaku pihak lain berdasarkan informasi masa lalu mengenai orang tersebut dan menghasilkan respon intuitif.

Pada impression validation terdapat perbedaan antara informan perempuan dan laki-laki karena informan perempuan memiliki keingintahuan yang lebih besar dibandingkan dengan informan laki-laki. Salah satu bentuk bentuk validasi yang dilakukan adalah dengan melakukan background check, namun informan laki-laki dalam penelitian ini tidak melakukan hal tersebut untuk mendapatkan informasi lebih dalam lagi mengenai calon intimate partner yang dikenalnya.

Kepercayaan untuk pada akhirnya berkomitmen ini diperoleh setelah melalui beberapa proses membangun kepercayaan selama berinteraksi dengan calon intimate partner. Hal ini tercermin dalam dimensi utama kepercayaan (Whitty \& Joinson, 2008) yaitu integritas dimana subjek percaya bahwa orang yang dipercaya dapat melakukan tindakan yang diharapkan serta dapat diandalkan. Dalam proses ini melibatkan proses kognitif dari trust-building pada intentionality process dan capability process, dimana intentionality process dipengaruhi oleh persepsi terhadap perilaku maupun perkataan (Doney dkk., 1998), yang dapat memunculkan ekspektasi atau harapan serta keinginan tertentu pada orang yang dipercaya dari asumsi yang telah dibuat. Kemudian pada capability process berkaitan dengan apakah kemampuan orang yang dipercaya sesuai dengan harapan orang yang mempercayai.

\section{I S K U S I}

Penelitian ini bertujuan untuk mengetahui bagaimana proses trust-building pada orang yang berinteraksi dan berkomunikasi menggunakan situs maupun aplikasi online dating. Dalam hasil analisis data, terdapat proses bagaimana kepercayaan terbangun selama interaksi maupun komunikasi antara ketiga subjek dengan orang-orang yang mereka kenali melalui situs perkencanan daring. Proses trustbuilding yang terjadi berawal dari motif serta intensi menggunakan situs perkencanan daring yang melibatkan bagaimana individu melakukan self-presentation dalam berinteraksi maupun membangun kepercayaan dengan orang lain sehingga mengarahkan pada terbangunnya kepercayaan antara dua orang tersebut.

Penelitian mengenai online dating sebenarnya telah dilakukan sebelumnya oleh beberapa peneliti. Seperti, penelitian mengenai dinamika dari internet dating yang membahas mengenai motivasi dan dan bagaimana pengguna online dating saling mengenal serta permasalahan mengenai trust dan penipuan yang terjadi. Penelitian ini menemukan bagaimana pengalaman partisipan serta kebebasan dalam memilih pasangan, meskipun adanya resiko yang dipertaruhkan dalam mengembangkan kepercayaan (Lawson \& Leck, 2006). Kemudian terdapat pula penelitian yang dilakukan oleh (M. Whitty \& Gavin, 2001) mengenai isyarat sosial dalam perkembagan hubungan online, lebih berfokus pada media online dating itu sendiri dan bagaimana isyarat sosial yang ada menciptakan arti dari online relationship. Penelitian tersebut dilakukan dengan pendekatan kualitatif dengan melakukan wawancara pada enam 
puluh partisipan, yang kemudian menghasilkan isyarat sosial yang ada dalam hubungan secara offline seperti trust, kejujuran, dan komitmen, juga sama pentingnya dengan hubungan yang terjalin secara online dan pada akhirnya dapat membentuk arti dari online relationship. Ada pula penelitian yang dilakukan pada tahun 2017 yang membandingkan bagaimana pengguna tiga platform online dating membentuk kepercayaan pada orang lain yang telah "match" sebelumnya pada 3 platform, yaitu match.com, Plenty of Fish (POF), dan Tinder (Obada-Obieh dkk., 2017).

Pokok persoalan atau bahasan yang dikaji dalam penelitian ini kurang lebih memiliki fokus yang sama seperti pada penelitian sebelumnya mengenai trust-building pengguna online dating ditinjau dari interaksi yang terjalin baik itu secara online maupun offline dan bahkan mungkin hingga mengarah pada romantic relationship. Meskipun terdapat beberapa penelitian yang mengkaji topik yang sama, namun penelitian ini dilakukan pada golongan anak muda di Indonesia dengan budaya masyarakat yang cenderung kolektivis (memiliki nilai tinggi pada grup/kelompok) (Mangundjaya, 2013), berbeda dengan penelitian sebelumnya yang memiliki kultur yang berbeda dengan Indonesia, yaitu cenderung individualis (Lawson \& Leck, 2006; Obada-Obieh dkk. 2017; Whitty \& Gavin, 2001).

Kolektivisme sendiri berkaitan dengan masyarakat yang dimana orang akan terintegrasi dalam pertalian yang kuat pada kelompok (Mangundjaya, 2013). Berbeda dengan sifat individualis yang menekankan pada right to privacy, kolektivis justru menekankan sharing (Brewer \& Chen, 2007). Walaupun memiliki perbedaan budaya didapatkan kesimpulan penelitian jika online dating (perkencanan dalam dunia maya) berawal dari motif dan intensi pengguna dalam menggunakan situs perkencanan daring hingga pada tahap intimacy munculah keterlibatan emosi kemudian mengarah pada pemuasan akan motif di awal menggunakan situs perkencanan daring yaitu komitmen. Meskipun tidak semua berakhir pada komitmen, tetapi ketiga partisipan berharap untuk dapat bersama dengan orang tertentu, hingga muncul keinginan akan adanya perubahan perilaku saat menjalin hubungan pacaran. Kepercayaan untuk pada akhirnya berkomitmen ini diperoleh setelah melalui beberapa proses membangun kepercayaan selama berinteraksi dengan calon intimate partner. Hal ini tercermin dalam dimensi utama kepercayaan (Whitty \& Joinson, 2008) yaitu, integritas dimana subjek percaya bahwa orang yang dipercaya dapat melakukan tindakan yang diharapkan serta dapat diandalkan. Dalam proses ini melibatkan proses kognitif dari trust-building pada intentionality process dan capability process, dimana dua hal tersebut dapat memunculkan ekspektasi atau harapan serta keinginan tertentu pada orang yang dipercaya dari asumsi yang telah dibuat dan berkaitan apakah kemampuan orang yang dipercaya sesuai dengan harapan orang yang mempercayai nya.

\section{S I M P U L A N}

Proses trust-building selama interaksi para pengguna situs perkencanan daring berawal dari intensi, kemudian melibatkan strategi self-presentation termasuk intensitas, media komunikasi, dan personality, lalu adanya kecocokan yang terlihat dari proximity, similarity, serta reciprocity. Pada akhirnya terdapat intimacy dan kepercayaan yang terwujud dalam bentuk komitmen. Meskipun demikian, proses yang terjadi pada tiap individu berbeda tergantung pada bagaimana interaksi antar individu dan karakteristik yang berbeda.

Dengan adanya situs dating yang dapat mempertemukan siapapun, pengguna situs tersebut diharapkan untuk berhati-hati lagi ketika menggunakan situs perkencanan daring dan berkenalan dengan orang asing karena tidak semua orang terutama orang asing yang baru ditemui dapat dipercaya. Termasuk untuk menjaga privasi ketika memberikan suatu informasi. 
Adapun saran untuk penelitian ini yang bisa peneliti selanjutnya lakukan yakni mewawancarai Partisipan penelitian secara langsung agar dapat mengobservasi bagaimana respon maupun kondisi situasional ketika bercerita supaya bisa mendapatkan gambaran Partisipan lebih detil dan sesuai data lapangan, kemudian meneliti aspek lain seperti rentang usia tertentu, atau kalangan tertentu, hingga status tertentu. Dengan begitu penelitian selanjutnya yang mungkin dilakukan dapat lebih terspesifikasi dan menggambarkan cakupan aspek tertentu dalam lingkup sosial. Hal-hal tersebut agar mampu memperkaya data penelitian dari partisipan lebih mendalam lagi agar hasil penelitian yang diperoleh dapat lebih menjelaskan secara detil pengalaman Partisipan terkait topik penelitian yang akan diteliti.

\section{UCAPAN TERIMA KASIH}

Terima kasih kepada seluruh partisipan yang telah bersedia atas berkontribusinya terhadap penelitian ini, terima kasih pula kepada Fakultas Psikologi Universitas Airlangga yang telah memfasilitasi penelitian ini, semoga manfaat penelitian ini bisa dirasakan secara luas khususnya pada bidang Psikologi.

\section{DEKLARASI POTENSI TERJADINYA KONFLIK KEPENTINGAN}

Theresia Christina Octaviolan dan Rahkman Ardi tidak bekerja, menjadi konsultan, memiliki saham, atau menerima dana dari perusahaan atau organisasi manapun yang mungkin akan mengambil untung dari diterbitkannya naskah ini.

\section{PUSTAKA ACUAN}

Brewer, M. B., \& Chen, Y. R. (2007). Where (Who) are collectives in collectivism? Toward conceptual clarification of individualism and collectivism. Psychological Review, 114(1), 133-151. https://doi.org/10.1037/0033-295X.114.1.133

Creswell, J. W. \& Poth, C.N. (2016). Qualitative Inquiry and Research Design: Choosing Among Five Traditions. SAGE Publications.

Creswell, J. W. \& Creswell, J.D. (2017). Research Design: Qualitative, Quantitative, and Mixed Methods Approaches, fourth edition. SAGE Publications.

Doney, P. M., Cannon, J. P., \& Mullen, M. R. (1998). Understanding the influence of national culture on the development of trust. Academy of Management Review, 23(3), 601-620. https://doi.org/10.5465/AMR.1998.926629

Jung, S., Roh, S., Yang, H., \& Biocca, F. (2017). Location and Modality Effects in Online Dating: Rich Modality Profile and Location-Based Information Cues Increase Social Presence, while Moderating the Impact of Uncertainty Reduction Strategy. Cyberpsychology, Behavior, and Social Networking, 20(9), 553-560. https://doi.org/10.1089/cyber.2017.0027

Kee, A. W., \& Yazdanifard, R. (2015). The Review of The Ugly Truth and Negative Aspects of Online Dating. Global Journal of Management And Business Research, 15(4), 31-36. https://www.journalofbusiness.org/index.php/GJMBR/article/view/1700

Lankton, N. K., Mcknight, D. H., \& Tripp, J. (2015). Technology, humanness, and trust: Rethinking trust in

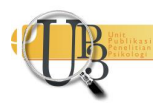


technology. Journal of the Association for Information Systems, 16(10), 880-918. https://doi.org/10.17705/1jais.00411

Lawson, H. M., \& Leck, K. (2006). Dynamics of Internet dating. Social Science Computer Review, 24(2), 189-208. https://doi.org/10.1177/0894439305283402

Mangundjaya, W. L. H. (2013). Is There Cultural Change in the National Cultures of Indonesia? Steering the Cultural Dynamics, July 2010, 59-68.

Margulis, S. T. (2011). Three theories of privacy: An overview. Privacy online, 9-17. https://doi.org/10.1007/978-3-642-21521-6

Obada-Obieh, B., Chiasson, S., \& Somayaji, A. (2017). "Don't Break My Heart!”: User Security Strategies for Online Dating (Short Paper). https://doi.org/10.14722/usec.2017.23046

Poerwandari, K., \& Hassan, F. (1999). Pendekatan Kualitatif untuk Penelitian Perilaku Manusia. Lembaga Pengembangan Sarana Pengukuran dan Pendidikan Psikologi (LPSP3).

Powell, G. (2013). Woman believed victim of online scam found dead. ABC News. https://www.abc.net.au/news/2013-03-04/woman-believed-victim-of-online-scam-founddead/4551050

Staff, Y. (2017). A third of Indonesians have use internet dating. Yougov. https://id.yougov.com/en$\mathrm{id} /$ news/2017/11/23/internet-dating/

Valkenburg, P. M., \& Peter, J. (2007). Who visits online dating sites? Exploring some characteristics of online daters. Cyberpsychology and Behavior, 10(6), 849-852. https://doi.org/10.1089/cpb.2007.9941

Whitty, M., \& Gavin, J. (2001). Age/Sex/Location: Uncovering the Social Cues in the Development of Online Relationships. CyberPsychology \& Behavior, 4(5), 623-630.

Whitty, M. T., \& Joinson, A. (2008). Truth, lies and trust on the internet. Routledge. 